\title{
TANAH LONGSOR : MEMPERKECIL RESIKO BENCANA MENGGUNAKAN SISTEM INFORMASI GEOGRAFIS ( Studi Kasus : Kecamatan Kokap, Kulon Progo, DIY )
}

\author{
Oleh : \\ Agus Aan Jiwa Permana ${ }^{1}$, Putu Perdana Kusuma Wiguna ${ }^{2}$ \\ Jurusan Manajemen Informatika, FTK, UNDIKSHA ${ }^{1}$ \\ Perencanaan Wilayah dan Kota, FT, $\mathrm{UNHI}^{2}$
}

\begin{abstract}
ABSTRAK
Setiap saat Indonesia mengalami ancaman bencana alam. Hal ini sudah dibuktikan dengan adanya bencana alam yang beruntun menimpa negara ini. Mulai dari tsunami, gunung meletus, banjir, tanah longsor, dan gempa. Dengan adanya halhal semacam ini, terpikirkan bagaimana caranya untuk melakukan pencegahan awal agar dampak kerugian material dan korban yang ditimbulkan dapat lebih diminimalisir. Misalnya saja bencana tanah longsor sering terjadi di Kabupaten Kulon Progo. Hal ini terjadi karena penambangan dan minimnya daerah tangkapan air sehingga menjadi penyebab maraknya kasus-kasus longsor di Kulon Progo baik karena aktivitas penambangan yang dilakukan legal atau ilegal. Khusus daerah yang menjadi sasaran penambangan emas di Yogya adalah Kecamatan Kokap. Sehingga menyebabkan banyak kejadian tanah longsor di daerah tersebut.

Dengan kondisi daerah yang sering mengalami bahaya longsor, nampaknya perlu dikembangkan sebuah sistem informasi geografis yang dapat membantu dalam manajemen resiko bencana tanah tanah longsor yang terjadi di Kecamatan Kokap, Kabupaten Kulon Progo. Sehingga nantinya jika sistem ini dapat dikembangkan, dapat membantu melakukan analisis resiko dari dampak bencana tanah longsor di era cyber seperti saat ini. Lokasi yang menjadi titik rawan bencana, diharapkan dapat dideteksi dan hasilnya dapat dianalisis untuk kepentingan lebih lanjut. Hasil dari penelitian ini adalah sudah dapat menghasilkan peta bahaya longsor dalam tiga kategori yaitu tinggi, sedang, dan rendah.
\end{abstract}

Kata-kata kunci: Tanah Longsor, Bencana Alam, Sistem Informasi Geografis.

\begin{abstract}
Every time when Indonesia experienced the threat of natural disasters. This is evidenced by the successive natural disasters that afflict this country. Start from tsunamis, volcanic eruptions, floods, landslides, and earthquakes. With the existence of this sort of thing, have you ever thought of how to do that early prevention and victim impact material losses incurred can be minimized. For example, landslides
\end{abstract}


often happen in Kulon Progo. This happens due to the lack of mining and the catchment area so that the cause of rampant cases of landslides in Kulon Progo well as mining activities are carried out legally or illegally. Target specific areas of gold mining in Yogya is Kokap. Causing widespread occurrence of landslides in the area.

To local conditions with frequent landslides, it seems necessary to develop a geographic information system that can assist in disaster risk management land landslides in Kokap, Kulon Progo Regency. So that if this system can be developed, can assist in the analysis of the impact of the risk of landslides in the cyber era. The location of the critical points of a disaster, is expected to be detected and the results can be analyzed for further interest. The results of this study are already able to produce a map of landslides in three categories: high, medium, and low.

Keywords : Landslide, Natural Disasters, Geographic Information Systems.

\section{PENDAHULUAN}

Setiap saat Indonesia mengalami ancaman bencana alam. Hal ini sudah dibuktikan dengan adanya bencana alam yang beruntun menimpa negara ini. Mulai dari tsunami, gunung meletus, banjir, tanah longsor, dan gempa. Dengan adanya halhal semacam ini, pernahkah terpikirkan bagaimana caranya untuk melakukan pencegahan sejak awal agar dampak kerugian material dan korban yang ditimbulkan dapat lebih diminimalisir. Tentu hal ini sangat mungkin dilakukan, misalnya saja seperti kejadian tsunami yang dialami oleh jepang beberapa hari lalu. Jika dilakukan manajemen resiko sebelumnya, kemudian berdasarkan analisis resiko yang ada memungkinkan untuk memperkecil jumlah korban jiwa dan kerugian yang ditimbulkan. Sistem yang dapat melakukan hal ini adalah sistem informasi geografi (SIG), karena dapat menyimpan dan mengolah informasi geografis (Susilo, 2002). SIG dapat digunakan dalam penentuan wilayah yang menjadi prioritas utama untuk penanggulangan bencana berikut penerapan standar bangunan yang sesuai, untuk mengidentifikasi struktur untuk retrofitting, untuk menentukan besarnya jaminan keselamatan terhadap masyarakat dan bangunan sipil, untuk mengidentifikasi sumber bencana, pelatihan dan kemampuan yang dimiliki secara spesifik terhadap bahaya yang dijumpai dan untuk mengidentifikasi area yang terkena banjir serta relokasi korban ke tempat yang aman (Haifani, 2008).

Tahun 2006 dan 2010 lalu, telah terjadi letusan gunung merapi di daerah yogyakarta, dan telah memakan banyak korban jiwa. Gempa bumi juga sering 
melanda Daerah Istimewa Yogyakarta (DIY), begitu juga dengan bencana tanah longsor. Bencana tanah longsor sering terjadi di Kabupaten Kulon Progo. Menurut Mustakim (2010) hal ini terjadi karena penambangan dan minimnya daerah tangkapan air sehingga menjadi penyebab maraknya kasus-kasus longsor di Kulon Progo. Aktivitas penambangan yang dilakukan dapat bersifat legal atau ilegal. Daerah yang menjadi sasaran penambangan emas di Yogya adalah Kecamatan Kokap. Sehingga menyebabkan banyak kejadian tanah longsor di daerah tersebut.

Dengan kondisi daerah yang sering mengalami bahaya longsor, di era cyber seperti saat ini nampaknya perlu dikembangkan sebuah sistem yang dapat membantu dalam manajemen resiko bencana tanah tanah longsor yang terjadi di Kecamatan Kokap, Kabupaten Kulon Progo. Sehingga nantinya sistem ini dapat membantu melakukan analisis resiko dari dampak bencana tanah longsor. Sistem diharapkan mampu memberikan informasi lokasi yang menjadi titik rawan bencana, untuk dapat dianalisis lebih lanjut.

\section{METODE PENELITIAN}

\subsection{Deskripsi Wilayah Kecamatan Kokap}

Kecamatan Kokap, terletak di Kabupaten Kulon Progo yang merupakan salah satu dari lima kabupaten kota di Propinsi Daerah Istimewa Yogyakarta (DIY) yang terletak paling barat. Secara geografis terletak antara $7^{\circ} 38^{\prime} 42^{\prime \prime}$ - 7 59'3" Lintang Selatan dan 110 1'37" - 110 16'26" Bujur Timur (Pemkab. Kulonprogo, 2010). Adapun letak dan perbatasan dari Kabupaten Kulon Progo adalah sebagai berikut :

Utara : Kabupaten Magelang, Propinsi Jawa Tengah

Timur : Kabupaten Sleman dan Bantul, Propinsi DIY

Selatan : Samudera Hindia

Barat : Kabupaten Purworejo, Propinsi Jawa Tengah

Dengan luas area 7.379,95 Ha, Kecamatan Kokap merupakan kecamatan memiliki daerah yang paling luas dibandingkan dengan kecamatan lain di Kabupaten Kulon Progo. Adapun kecamatan yang paling kecil wilayahnya adalah Kecamatan Wates yaitu 3.200,239 Ha. Hal ini dapat ditunjukan seperti Tabel 1. Sebagai kecamatan, 
Kokap memiliki lima kelurahan, antara lain : Hargorejo, Hargowilis, Hargomulyo, Kalirejo, dan Hargotirto.

Tabel 1. Luas Wilayah dan Persentase Luas Wilayah Kecamatan (Sumber : Pemkab. Kulonprogo, 2010)

\begin{tabular}{|l|l|l|l|}
\hline No. & Nama Kecamatan & Luas Wilayah (Ha) & Persentase \\
\hline 1 & Temon & $3,629.890$ & 6.191 \\
\hline 2 & Wates & $3,200.239$ & 5.459 \\
\hline 3 & Panjatan & $4,459.230$ & 7.606 \\
\hline 4 & Galur & $3,291.232$ & 5.614 \\
\hline 5 & Lendah & $3,559.192$ & 6.071 \\
\hline 6 & Sentolo & $5,265.340$ & 8.981 \\
\hline 7 & Pengasih & $6,166.468$ & 10.518 \\
\hline 8 & Kokap & $7,379.950$ & 12.588 \\
\hline 9 & Girimulyo & $5,490.424$ & 9.365 \\
\hline 10 & Nanggulan & $3,960.670$ & 6.756 \\
\hline 11 & Kalibawang & $5,296.368$ & 9.034 \\
\hline 12 & Samigaluh & $6,929.308$ & 11.819 \\
\hline & Total : & $\mathbf{5 8 , 6 2 7 . 5 1 2}$ & $\mathbf{1 0 0 . 0 0 0}$ \\
\hline
\end{tabular}

Secara fisiografis kondisi Kecamatan Kokap luas wilayah kokap berdasarkan ketinggian di atas permukaan laut dapat dilihat pada Tabel 2. Sedangkan luas wilayah menurut kemiringannya dapat dilihat pada Tabel 3.

Tabel 2. Luas Wilayah Kokap Menurut Ketinggian dari Permukaan Laut (Sumber : Pemkab. Kulonprogo, 2010)

\begin{tabular}{|c|c|c|c|c|c|}
\hline \multirow{2}{*}{$\begin{array}{c}\text { Luas Wilayah } \\
\text { (Ha) }\end{array}$} & \multicolumn{5}{|c|}{ Ketinggian (Meter) } \\
\cline { 2 - 6 } & $<7$ & $8-25$ & $26-100$ & $101-500$ & $<500$ \\
\cline { 2 - 6 } & - & 284 & 756 & 6,150 & 190 \\
\hline
\end{tabular}

Tabel 3. Luas Wilayah Kokap Menurut Kemiringan (Sumber : Pemkab. Kulonprogo, 2010)

\begin{tabular}{|c|c|c|c|c|}
\hline \multirow{2}{*}{$\begin{array}{c}\text { Luas Wilayah } \\
(\text { Ha) }\end{array}$} & \multicolumn{4}{|c|}{ Kemiringan (derajat) } \\
\cline { 2 - 5 } & $<2^{\circ}$ & $3^{\circ}-15^{\circ}$ & $16^{\circ}-40^{\circ}$ & $<40^{\circ}$ \\
\cline { 2 - 5 } & 284 & 858 & 2,603 & 3,635 \\
\hline
\end{tabular}




\subsection{Sistem Informasi Geografis (SIG)}

Sistem informasi geografis (SIG) pertama kali dikembangkan oleh Tomlinson pada tahun 1967. Namun, dalam perkembangan selanjutnya, terdapat beberapa definisi tentang SIG antara lain :

1. Sistem yang digunakan untuk memasukan, menyimpan, memanggil kembali, mengolah menganalisis, dan menghasilkan data bereferensi geografis atau data geospatial, untuk mendukung pengambilan keputusan dalam perencanaan dan pengelolaan sumber daya alam, lingkungan, transportasi, fasilitas kota, dan pelayanan umum lainnya (Murai, 1999 dalam Elly, 2009 : 3).

2. Sistem yang berbasiskan komputer yang digunakan untuk menyimpan data dan manipulasi informasi-informasi geografi (Aronoff, 1993 dalam Elly, $2009: 3$ ).

3. Sistem komputer yang digunakan untuk memanipulasi data geografi (Berhardsen, 2002 dalam Elly, 2009 : 3).

Sistem ini selanjutnya diimplementasikan dengan perangkat keras dan perangkat lunak komputer yang berfungsi untuk akuisisi, verifikasi data, kopilasi data, penyimpanan data, perubahan dan pembaharuan data, manajemen dan pertukaran data, manipulasi, pemanggilan dan presentasi data serta analisa data. Dengan adanya beberapa definisi dari SIG, pada prinsipnya SIG tidak dapat lepas dari perangkat keras dan perangkat lunak komputer serta manajemen data dan informasi tentang permukaan bumi.

Berdasarkan definisi dan pengertian yang tersebut diatas SIG dapat diuraikan ke dalam beberapa subsistem yaitu :

1. Data Input (memasukan data)

Subsistem ini berfungsi mengumpulkan data spasial dan data atribut dari berbagai sumber, sekaligus bertanggungjawab dalam merubah atau memformat data aslinya kedalam format yang dapat digunakan untuk SIG.

\section{Data Management (Strorage and Retrieval)}

Subsistem ini mengorganisasikan baik data spasial maupun data atribut kedalam sebuah basis data sedemikian rupa sehingga mudah dipanggil, di update dan di edit.Jadi subsistem ini dapat menimbun dan menarik kembali 
dari arsip data dasar, juga dapat melakukan perbaikan data dengan cara menambah, mengurangi atau memperbaharui.

3. Data Manipulation and Analysis

Subsistem ini menentukan inforamasi yang dapat dihasilkan oleh Sig. Subsistem ini juga dapat melakuakan memanipulasi dan permodelan data untuk menghasilkan informasi data.

\section{Data Output (Reporting)}

Berfungsi menanyangkan informasi dan hasil analisis data geografis secara kualitatif maupun kuantitatif atau dapat berfungsi menampilkan atau menghasilkan keluaran seluruh atau sebagian basis data dalam bentuk softcopy maupun dalam bentuk hardcopy, seperti tabel, grafik, dan peta arsip elektronik.

\subsection{Pemodelan Data Spasial Dan Non Spasial}

Dalam kasus ini, SIG dikembangkan untuk mengetahui daerah yang rawan akan bencana tanah longsor di Kecamatan Kokap, Kabupaten Kulon Progo. Sehingga dalam hal ini perlu adanya parameter untuk mengkaji akan adanya tanah longsor. Parameter yang dimaksud antara lain: jenis tanah, tingkat kemiringan lereng, dan tata guna lahan di wilayah Kokap seperti Gambar 1. Pada prinsipnya tanah longsor terjadi bila gaya pendorong pada lereng lebih besar dari gaya penahan (Kementerian ESDM, 2008).

Gaya penahan umumnya dipengaruhi oleh kekuatan batuan dan kepadatan tanah. Sedangkan gaya pendorong dipengaruhi oleh besarnya sudut kemiringan lereng, air, beban serta berat jenis tanah batuan. Ancaman tanah longsor biasanya terjadi pada bulan November, karena meningkatnya intensitas curah hujan. Musim kering yang panjang menyebabkan terjadinya penguapan air di permukaan tanah dalam jumlah besar, sehingga mengakibatkan munculnya pori-pori atau ronggarongga dalam tanah, yang mengakibatkan terjadinya retakan dan rekahan permukaan tanah. Adapun alasan menggunakan ketiga parameter tersebut karena, menurut Kementrian ESDM (2008) mengungkapkan beberapa penyebab terjadinya longsor yaitu antara lain : 
1. Lereng Terjal : Lereng atau tebing yang terjal akan memperbesar gaya pendorong. Lereng yang terjal terbentuk karena pengikisan air sungai, mata air, air laut, dan angin. Kebanyakan sudut lereng yang menyebabkan longsor adalah 1800 apabila ujung lerengnya terjal dan bidang longsorannya mendatar.

2. Tanah yang Kurang Padat dan Tebal : Jenis tanah yang kurang padat adalah tanah lempung atau tanah liat dengan ketebalan lebih dari 2,5 $\mathrm{m}$ dan sudut lereng lebih dari 220. Tanah jenis ini memiliki potensi untuk terjadinya tanah longsor terutama bila terjadi hujan. Selain itu tanah ini sangat rentan terhadap pergerakan tanah karena menjadi lembek terkena air dan pecah ketika hawa terlalu panas.

3. Batuan yang Kurang Kuat : Batuan endapan gunung api dan batuan sedimen berukuran pasir dan campuran antara kerikil, pasir, dan lempung umumnya kurang kuat. Batuan tersebut akan mudah menjadi tanah bila mengalami proses pelapukan dan umumnya rentan terhadap tanah longsor bila terdapat pada lereng yang terjal.

4. Jenis Tata Lahan : Tanah longsor banyak terjadi di daerah tata lahan persawahan, perladangan, dan adanya genangan air di lereng yang terjal. Pada lahan persawahan akarnya kurang kuat untuk mengikat butir tanah dan membuat tanah menjadi lembek dan jenuh dengan air sehingga mudah terjadi longsor. Sedangkan untuk daerah perladangan penyebabnya adalah karena akar pohonnya tidak dapat menembus bidang longsoran yang dalam dan umumnya terjadi di daerah longsoran lama.

Dunia Nyata

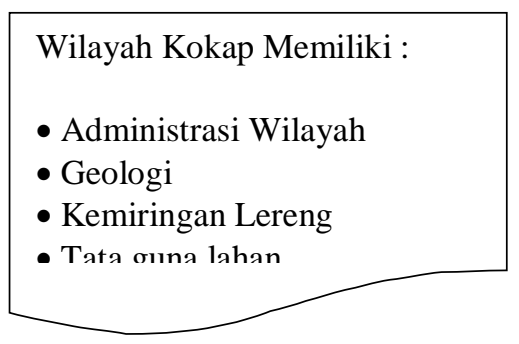

Representasi Dunia Nyata

Dalam SIG

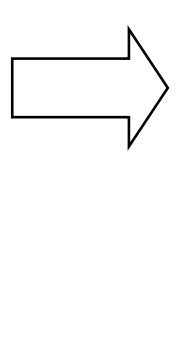

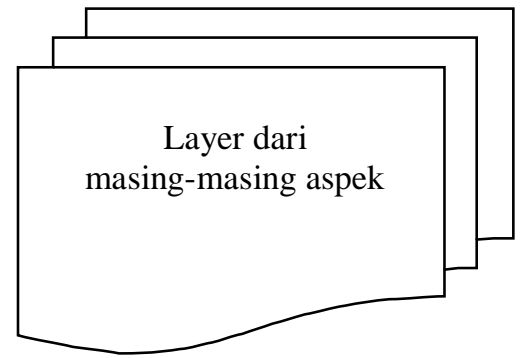

Gambar 1. Representasi Dunia Nyata Dalam SIG

Tanah Longsor : Memperkecil Resiko..( Agus Aan J. P. dan Putu Perdana K. W.) 
Adapun hasil akhir yang diharapkan adalah dapat melakukan analisis spasial terhadap kondisi yang miliki wilayah Kokap. Sehingga apabila terjadi bencana tanah longsor, sudah dapat diperkirakan dari sebelumnya. Pemerintah diharapkan dapat mengambil sikap lebih awal, sehingga kerugian material dan jumlah korban jiwa dapat diminimlisir sekecil mungkin. Gambaran SIG yang dikembangkan dapat diilustrasikan sebagai Gambar 1.

\subsection{Rancangan Basis Data Sistem}

Dalam membangun sistem ini, data yang digunakan berasal dari beberapa sumber yang menghasilkan kombinasi dari data spasial dan non spasial seperti yang digambarkan pada Gambar 2. Adapun sumber data yang digunakan dalam sistem dapat dilihat pada Tabel 4.

Tabel 4. Sumber Data untuk SIG

\begin{tabular}{|l|l|}
\hline \multicolumn{1}{|c|}{ Jenis Data } & \multicolumn{1}{c|}{ Sumber Data } \\
\hline Batas Administratif Pemerintahan & $\begin{array}{l}\text { Peta RBI Wilayah Administratif Kabupaten } \\
\text { Kulon Progo }\end{array}$ \\
\hline Tata Guna Lahan & Kokap (2009) \\
\hline Jalan & Peta Analog RBI Bakosurtanal \\
\hline Sungai & Peta Analog RBI Bakosurtanal \\
\hline Geologi & Sartohadi dan Putri (2010) \\
\hline Kemiringan lereng & Sartohadi dan Putri (2010) \\
\hline
\end{tabular}

Tahapan pembangunan topologi diawali dengan proses scaning terhadap peta-peta analog yang telah dikumpulkan. Selanjutnya dilakukan digitasi pada peta yang telah di scan menggunakan software ArcView 3.3. Pembagian wilayah kelurahan di Kokap dapat dilihat seperti Gambar 3. Adapun repesentasi data SIG dapat dilihat pada Tabel 5 . 


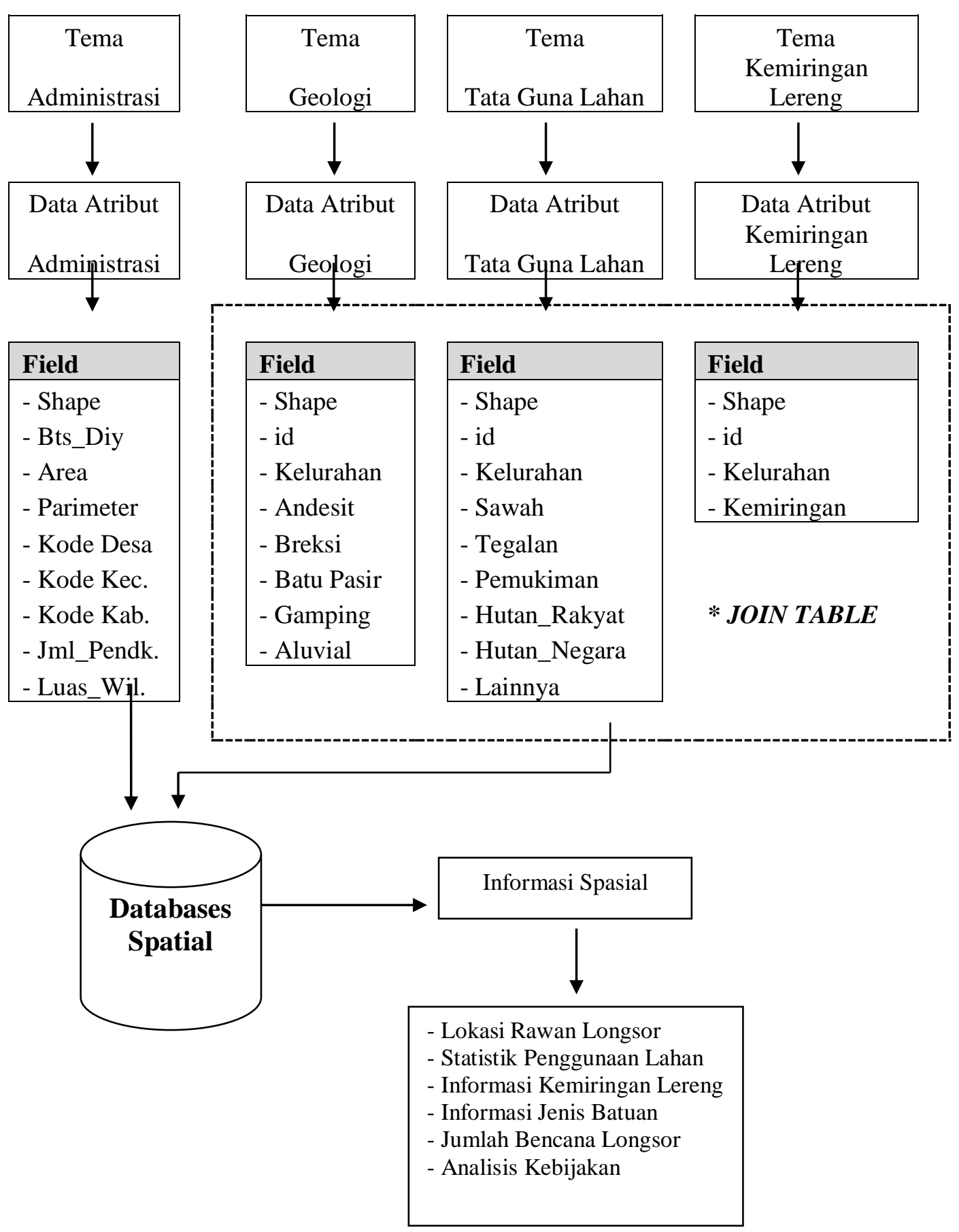

Gambar 2. Kombinasi Data Spasial dan Non Spasial Sistem

Tanah Longsor : Memperkecil Resiko..( Agus Aan J. P. dan Putu Perdana K. W.) 


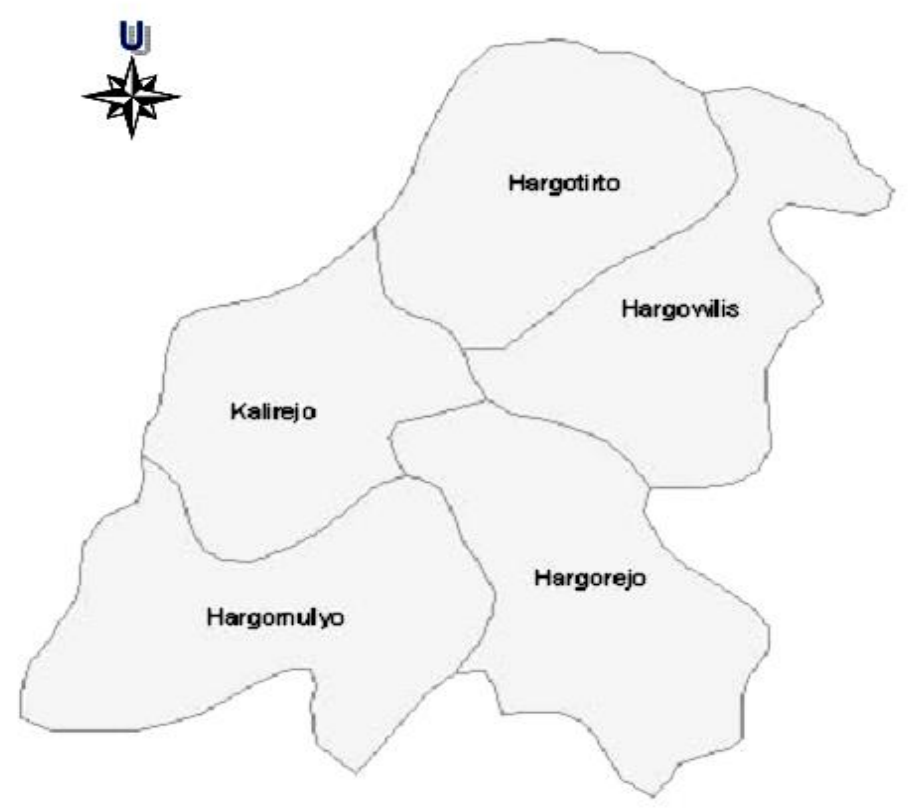

Gambar 3. Peta Kecamatan Kokap

Tabel 5. Representasi Data Spasial dan Non Spasial Detail

\begin{tabular}{|l|c|l|}
\hline \multicolumn{1}{|c|}{ Jenis Data } & $\begin{array}{c}\text { Representasi Data } \\
\text { Spasial Dalam GIS }\end{array}$ & Keterangan Data Non Spasial \\
\hline $\begin{array}{l}\text { - Batas } \\
\text { Administratif }\end{array}$ & Peligon & $\begin{array}{l}\text { Nama Kelurahan, dan Luas } \\
\text { Wilayah }\end{array}$ \\
\hline - Tata Guna Lahan & Poligon & $\begin{array}{l}\text { Batas Administrasi, Nama Desa, } \\
\text { Sawah, Tegalan, Pemukiman, } \\
\text { Hutan Rakyat \& Negara, dan } \\
\text { yang Lainnya }\end{array}$ \\
\hline - Jalan & Garis & - \\
\hline - Sungai & Garis & - \\
\hline - Geologi & Poligon & $\begin{array}{l}\text { Berisi data jenis batuan Aluvial, } \\
\text { Batu Gamping, } \\
\text { Batu Pasir, Andesit, } \\
\text { Breksi }\end{array}$ \\
\hline
\end{tabular}

Berdasarkan Tabel 5 dapat dilihat lebih jelas lagi representasi dari data spasial yang dimana batas administrasi, tata guna lahan dan geologi direpresentasikan dalam bentuk poligon, sedangkan untuk jalan dan sungai direpresentasikan dalam bentuk 
garis. Informasi data non spasial yang dapat diberikan sistem antara lain, nama kelurahan beserta luas wilayahnya, luas tata guna lahan di masing-masing kelurahan(Ha) yang berupa sawah, tegalan, pemukiman, hutan rakyat \& negara, serta penggunaaan lahan untuk lainnya. Kemudian berapa prosentase jenis batuan di jadikan skor dalam rentangan 0, 1, 2 dan 3 .

\section{HASIL DAN PEMBAHASAN}

Setelah melakukan digitasi peta, dapat dihasilkan sebuah peta administrasi Kecamatan Kokap yang meliputi batas desa, batas kecamatan, batas propinsi, garis pantai, sungai, serta jalan. Masing-masing kelurahan diberikan warna yang berbeda untuk lebih detailnya dapat dilihat pada Gambar 4. Melalui proses overlay dari beberapa layer dari ketiga parameter dapat menghasilkan peta untuk mengetahui tingkat bahaya tanah longsor yang memiliki tiga kategori : tinggi, rendah, dan sedang seperti Gambar 5, yang nantinya dapat digunakan sebagai bahan untuk analisis lebih lanjut.

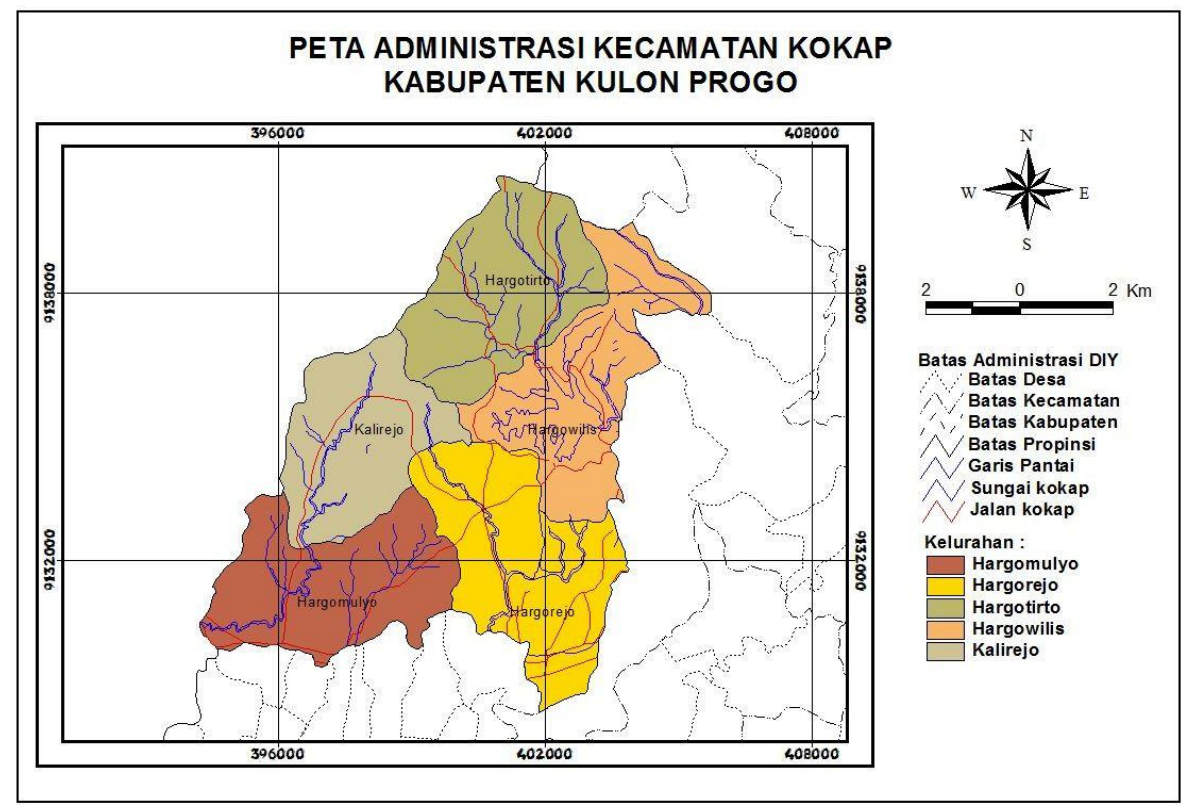

Gambar 4. Peta Administrasi Kokap

Tanah Longsor : Memperkecil Resiko..( Agus Aan J. P. dan Putu Perdana K. W.) 


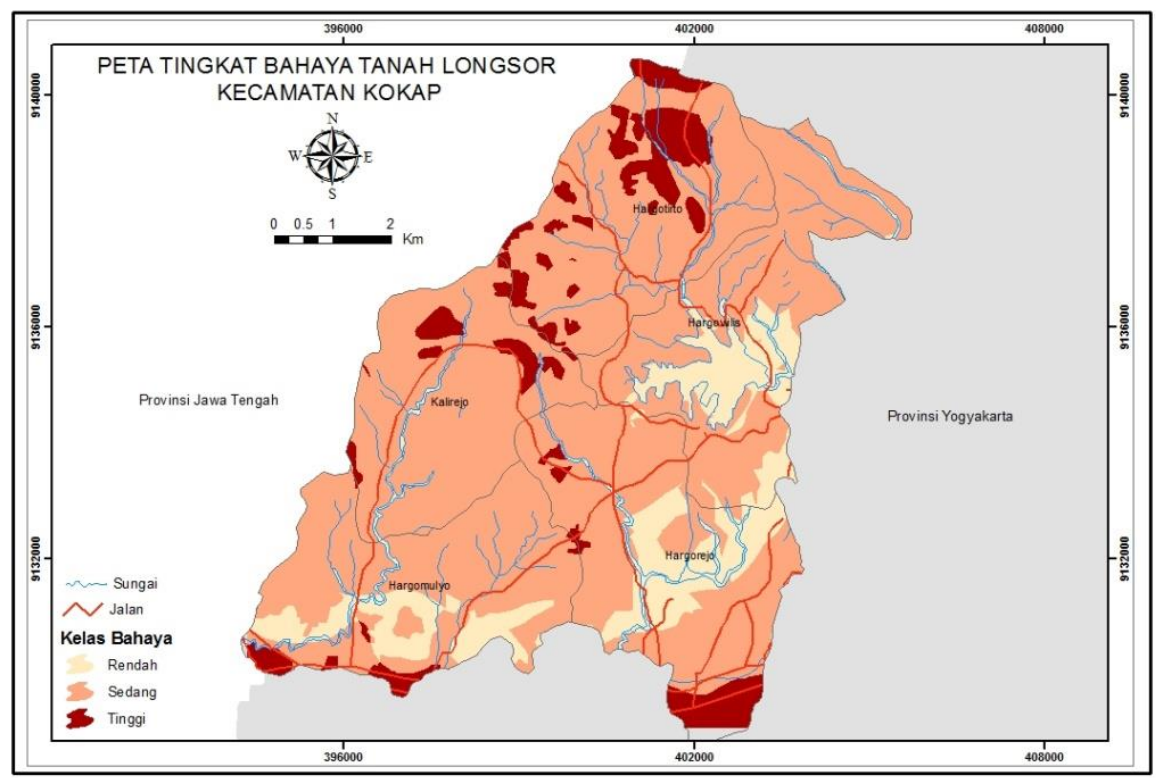

Gambar 5. Peta Tingkat Bahaya Tanah Longsor

\section{PENUTUP}

Berdasarkan data yang diperoleh dari berbagai macam sumber, telah mampu dikembangkan sebuah SIG yang dapat digunakan untuk membantu pemerintah, masyarakat, serta khalayak umum tentang kerawanan lokasi longsor di Kecamatan Kokap, Kulon Progo, Yogyakarta. Gambar 5 menunjukan wilayah kelurahan yang kemungkinan terkena tanah longsor yang paling tinggi adalah Hargotirto dan Kalirejo (warna merah). Sedangkan yang kemungkinan megalami longsor sedang meliputi kelima buah kelurahan (warna merah muda). Apabila akan mendirikan pabrik, bangunan, dan pemukiman penduduk diharapkan di seputaran daerah yang berwarna putih karena relatif aman dari longsor. Sehingga diharapkan pemerintah dapat mengeluarkan kebijakan, terkait dengan keadaan di daerah yang rawan bencana longsor tersebut supaya korban dapat diminimalisir serta meningkatkan himbauan ke warga tentang bahaya tanah longsor baik sosialisasi langusng/cyber. 


\section{DAFTAR PUSTAKA}

Kokap, 2009, Kecamatan Kokap Dalam Angka 2009, No.ISSN: 0852.0274 Yogyakarta : Badan Pusat Statistik Kabupaten Kulon Progo

Susilo, Eko, 2002, Suatu Aplikasi SIG Web, Teknik Geodesi UGM, Yogyakarta.

Haifani, A. M., 2008, Aplikasi Sistem Informasi Geografi Untuk Mendukung Penerapan Sistem Manajemen Resiko Bencana Di Indonesia, Seminar Nasional Sains dan Teknologi-II, Tanggal 17-18 November, Lampung.

Mustakim, 2010, Penambangan Picu Maraknya Longsor di Kulon Progo, www.greenradio.fm, (Diakses : 14 Maret 2011, 10:21).

Elly, M. J., 2009, Sistem Informasi Geografis Menggunakan Aplikasi ArcView 3.2 dan ERMapper 6.4, Edisi I, Yogyakarta : Graha Ilmu

Kementerian ESDM, 2008, Faktor-faktor Penyebab Tanah Longsor, http://www.esdm.go.id/berita/geologi/42-geologi/1162-faktor-faktorpenyebab-tanah-longsor.html, (Diakses : 12 Agustus 2013, 10:31)

Kementerian $\quad$ ESDM, 2008, Tersedia pada ttp://repository.usu.ac.id/bitstream/123456789/21974/4/Chapter \%20II.pdf, (Diakses : 12 Agustus 2013, 10:40)

Sartohadi, J., Dan Putri, R.F., 2010, Evaluasi Potensi Degradasi Lahan Dengan Menggunakan Analisa Kemampuan Lahan Dan Tekanan Penduduk Terhadap Lahan Pertanian Di Kecamatan Kokap Kabupaten Kulon Progo, Jurusan Geografi dan Ilmu Lingkungan, Fak. Geografi UGM, Yogyakarta.

Tanah Longsor : Memperkecil Resiko..( Agus Aan J. P. dan Putu Perdana K. W.) 
JPTK, UNDIKSHA, Vol. 9, No. 1, Januari 2012 : 47 - 60 